\title{
STRUCTURAL CHANGES IN METAL OF WELDED JOINTS OF STEAM PIPELINES IN OPERATION
}

\author{
V.V. DMITRIK ${ }^{1}$, O.V. SOBOL ${ }^{1}$, M.A. POGREBNOJ ${ }^{1}$, A.V. GLUSHKO ${ }^{1}$ and G.I. ISHCHENKO ${ }^{2}$ \\ ${ }^{1}$ NTU «Kharkov Polytechnic Institute» \\ 21 Frunze Str., 61022, Kharkov, Ukraine. E-mail: svarka126@ukr.net \\ ${ }^{2}$ OJSC «Turboatom»
}

199 Moskovsky Ave., Kharkov, Ukraine. E-mail: office@turboatom.com.ua

\begin{abstract}
Extension of service life of steam pipelines is a relevant task. Investigation of peculiarities of structural state in metal of welded joints of long-lasting operation steam pipelines allows evaluating a level of their damageability and grounding residual life. This study determined that structural changes of welded joints from $15 \mathrm{Kh} 1 \mathrm{M} 1 \mathrm{~F}$ and $12 \mathrm{Kh} 1 \mathrm{MF}$ steels are caused by diffusion processes, formation of intergranular segregations, carbide reactions, nucleation and propagation of creep pores. The ways are outlined for regulation of structural state of metal of HAZ areas, which are directed at reduction of structural inhomogeneity and extension of service life. 10 Ref., 10 Figures.
\end{abstract}

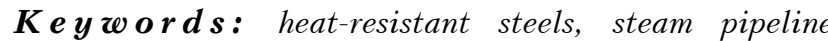
welded joints, structure, carbides, pores, damageability, diffusion, deformation, heat-affected zone

Degradation of metal of long-lasting operation steam pipelines from $15 \mathrm{Kh} 1 \mathrm{M} 1 \mathrm{~F}$ and $12 \mathrm{Kh} 1 \mathrm{MF}$ steels is provided by physical-chemical processes taking place in them. Intensity of such processes, promoting structural changes in metal of the welded joints, is higher than in the base metal. It is caused by presence of initial structural, chemical and mechanical inhomogeneity being formed under the effect of welding heat. The level of inhomogeneity in the welded joints is significantly higher than in the base metal.

Chemical, structural and mechanical inhomogeneity of metal of welded joints receive further development in processes of operation of the steam pipeline, in particular after $250,000 \mathrm{~h}$ of running. From our point of view, inhomogeneity of each type at first shall be studied separately for further investigation of their general effect on welded joint degradation.

Aim of the work lies in study of peculiarities of structural changes of metal of the long-lasting operation welded joints from $15 \mathrm{Kh} 1 \mathrm{M} 1 \mathrm{~F}$ and $12 \mathrm{Kh} 1 \mathrm{MF}$ steels, that allows evaluating the level of their damageability and specifying residual life.

Weld metal and areas of HAZ of welded joints from given heat-treatable steels can have initial (after high-tempering) sorbite, ferrite-bainite, ferrite-sorbite structures as well as other structures allowed by reference documents [1-4]. The highest level of structural and mechanical inhomogeneity has an area with incomplete re-crys- tallization of HAZ metal, where new products of austenite decay in the initial structure represent (depending on welding heat) pearlite, sorbite, troostite or even martensite. It is relevant to produce welded joints with probably smaller structural inhomogeneity by means of welding heat optimizing, for example, ferrite-bainite or bainite weld metal structure [5-7].

Structures of the welded joints in process of long-lasting operation under creep conditions (temperature of operation $T_{\mathrm{op}}=545-585{ }^{\circ} \mathrm{C}$, operating pressure $P_{\text {op }}=20-25 \mathrm{MPa}$ ) are transformed with various intensity into different on content ferrite-carbide mixtures. Intensity of structural changes, significantly depending on their initial condition, to the most extent after more than $250,000 \mathrm{~h}$ of running of welded joint, is obvious in areas of fusion, overheating and incomplete re-crystallization of HAZ metal [8, 9]. Structural changes are caused by diffusion displacement of chromium and molybdenum from central zones of $\alpha$-phase crystals in their nearboundary zones (volumetric diffusion) and diffusion displacement of given elements over the grain boundaries (grain-boundary diffusion) as well as formation of segregations in the nearboundary zones of crystallites and displacement of dislocations by means of glide and climb, that resulted in appearance of fragmentation (polygonization) of $\alpha$-phase grains; by transfer of chromium and molybdenum from $\alpha$-phase into carbides as well as formation of new carbides VC and $\mathrm{Mo}_{2} \mathrm{C}$; passing of carbide reactions $\mathrm{M}_{3} \mathrm{C} \rightarrow$ $\rightarrow \mathrm{M}_{7} \mathrm{C}_{3} \rightarrow \mathrm{M}_{23} \mathrm{C}_{6}$; coagulation of carbide phases of the 1st group; nucleation and propagation of 


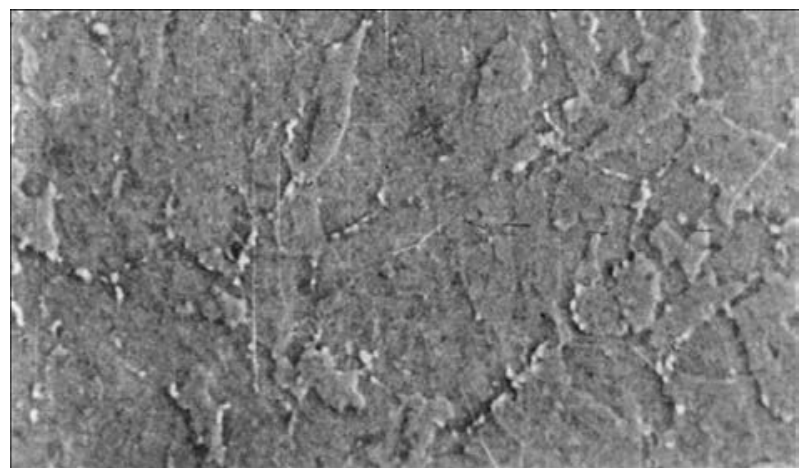

Figure 1. Carbide precipitates in initial structure of areas of HAZ metal incomplete re-crystallization of welded joint from steel $15 \mathrm{Kh} 1 \mathrm{M} 1 \mathrm{~F}(\times 2500)$

creep micropores as well as their transformation in macropores and macrocracks. Each of indicated processes, respectively, promotes for change of metal structure in the welded joints, that in total determines its degradation and reduction of heat resistance. In this connection, damageability on corrosion-fatigue mechanism requires separate consideration.

Initial structure of $15 \mathrm{Kh} 1 \mathrm{M} 1 \mathrm{~F}$ and $12 \mathrm{Kh} 1 \mathrm{MF}$ steels (Figure 1) contains carbides of the 1st group $\mathrm{M}_{3} \mathrm{C}$ (mainly), $\mathrm{M}_{7} \mathrm{C}_{3}$ and $\mathrm{M}_{23} \mathrm{C}_{6}$ (small amount) as well as $2 \mathrm{~d}$ group ones, namely fine $\mathrm{VC}$ carbides in $\alpha$-phase grain body and in their interfaces. Initially they have circular or acicular (VC) form.

In process of aging, self-diffusion of chromium and molybdenum from central zones of $\alpha$-phase grains in their near-boundary zones provokes change of bonding forces between the atoms. Diffusion displacement of atoms of chromium and molybdenum, caused by gradients of their chemical potentials, results in formation of near-boundary segregation zones in $\alpha$-phase crystals $[8,9]$. Presence of such zones develops the conditions for carbide reactions $\mathrm{M}_{3} \mathrm{C} \rightarrow \mathrm{M}_{7} \mathrm{C}_{3} \rightarrow \mathrm{M}_{23} \mathrm{C}_{6}$ as well as coagulation of $\mathrm{M}_{7} \mathrm{C}_{3}$ carbides and, mainly, $\mathrm{M}_{23} \mathrm{C}_{6}$. The coagulation of carbides along the grain interface takes place by means of coalescence, that results in formation of elongated, with possible branching, carbide forms ( $\mathrm{Fi}^{-}$ gure 2). Coagulating (with lower intensity) $\mathrm{M}_{7} \mathrm{C}_{3}$ and $\mathrm{M}_{23} \mathrm{C}_{6}$ carbides, which are located in $\alpha$-phase grain body, mainly have the form close to circular one. Vanadium carbide $\left(a_{0}=\right.$ $=0.416 \mathrm{~nm}$ ) remains stable to $290,000 \mathrm{~h}$ of running [7]. Stability of dispersed vanadium carbides is one of the factors determining life of these steels.

Irregular chains (Figure 3) are formed from elongated $\mathrm{M}_{7} \mathrm{C}_{3}$ and $\mathrm{M}_{23} \mathrm{C}_{6}$ carbides, having diameter of around $0.15-0.30 \mu \mathrm{m}$, along the $\alpha$ phase grain interface in process of aging $\left(t_{\mathrm{op}}>\right.$

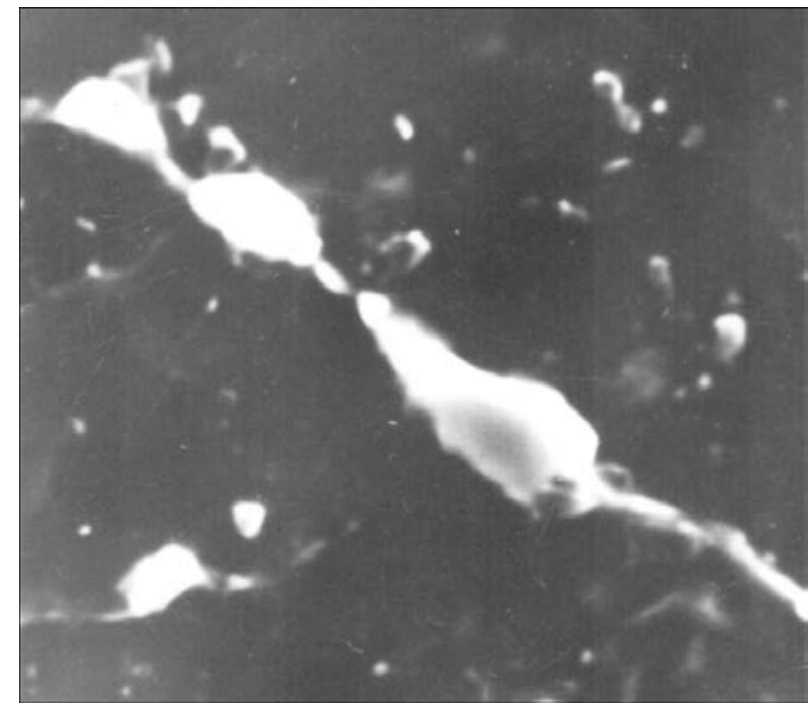

Figure 2. Coagulation by means of coalescence of $\mathrm{M}_{23} \mathrm{C}_{6}$ carbides on $\alpha$-phase grain interface $(\times 4000)$

$>270,000$ h). Given carbides have close crosssection dimensions and significantly different lengths.

It can be outlined that $\mathrm{M}_{7} \mathrm{C}_{3}$ and $\mathrm{M}_{23} \mathrm{C}_{6}$ carbides of elongated form located at grain interface have decisive effect on brittleness. For example, impact toughness of the welded joint of steam pipelines, operating under conditions of main steam and having metal structure given in $\mathrm{Fi}^{-}$ gure 3 , made $K C U=31 \mathrm{~J} / \mathrm{cm}^{2}$ and that of the base metal with uniformly distributed carbides was $K C U=74 \mathrm{~J} / \mathrm{cm}^{2}$. It is found that coagulation of carbide phases along the grain interface promotes for further reduction of impact toughness to the value below allowed one [1-4]. In course of long-lasting running ( $t_{\mathrm{op}}>>250,000 \mathrm{~h}$ ) of chromium and molybdenum diffusing from $\alpha$-phase form new carbides ( $\mathrm{VC}$ and $\mathrm{Mo}_{2} \mathrm{C}$ ) as well as transfer into the 1st group carbides, mainly in

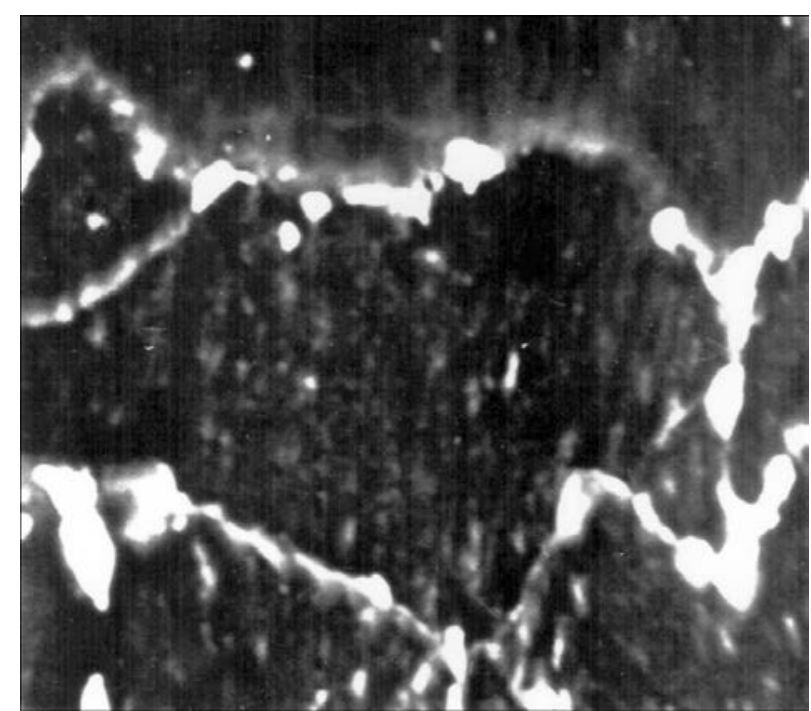

Figure 3. Distribution of $\mathrm{M}_{23} \mathrm{C}_{6}$ carbides on $\alpha$-phase grain interface $(\times 2500)$ 


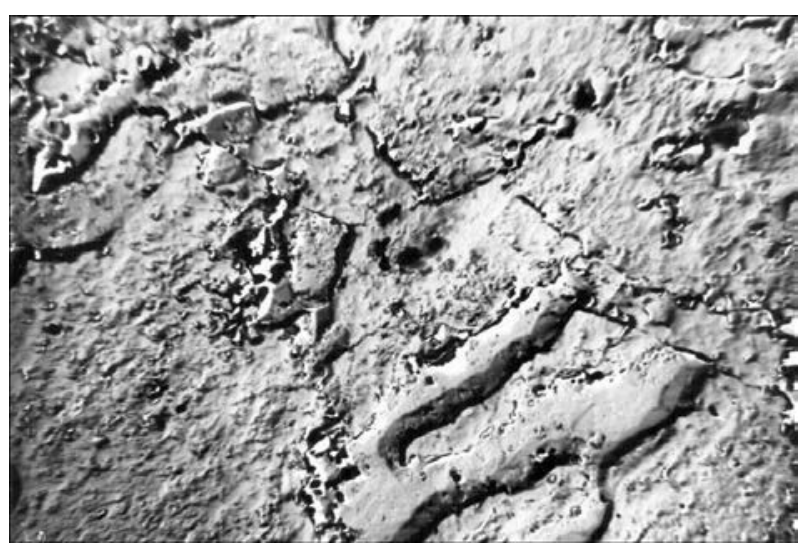

Figure 4. Microstructure $(\times 4500)$ of grain in area of HAZ metal overheating

$\mathrm{M}_{23} \mathrm{C}_{6}$. It is determined that total content of alloying elements in the carbides in metal of HAZ overheating area after $270,000 \mathrm{~h}$ running made 60-65\% Cr, 70-75\% Mo and 80-82\% V. Different length of carbides, from our point of view, is caused by varying rate of their lattice build-up that is related with the level of segregation of chromium and molybdenum in the near-boundary $\alpha$-phase zones, and their diffusion displacement. Difference in diffusion displacement intensity is typical for volumetric as well as grain-boundary diffusion. Increase of the near-boundary segregation zones on width, in our opinion, is mainly provided by means of volumetric diffusion, and their length is caused by grain-boundary diffusion. Periodic change of transfer direction of separate atoms of chromium and molybdenum at stated general direction of their diffusion displacement is noted in the processes of long-term aging. This corresponds to fillet diffusion mechanism [10] which is type of vacancy mechanism. Realization of transfers of studied mechanism seems to be possible only in presence of the fillet-like vacancies.

Process of aging increases diffusion mobility of the vacancies as well as mobility of disloca-

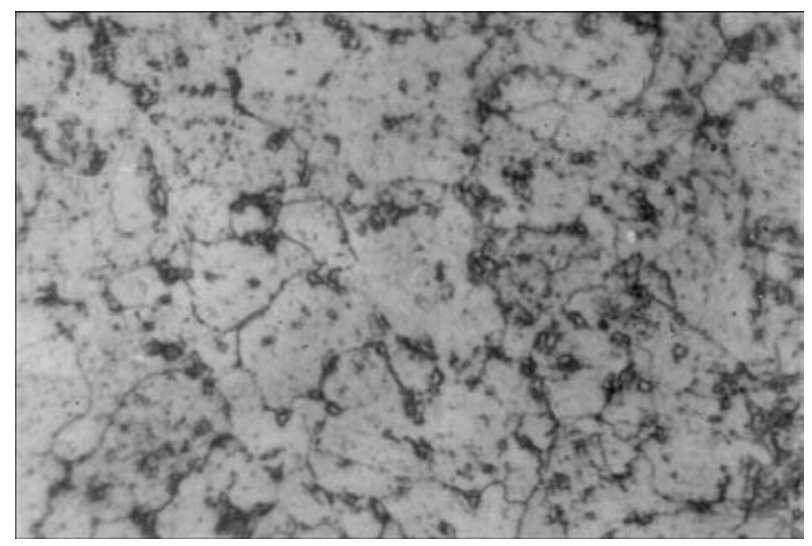

Figure 5. Microstructure $(\times 360)$ of area of HAZ metal incomplete re-crystallization with new products of austenite decay which represent themselves globular pearlite tions, which displace by means of glide and climb.

Metallographic method was used for dislocation detection. It allowed determining places of dislocation emergence on working surface of microsection. Also method of transmission microscopy was used that provided the possibility of qualitative evaluation of dislocation density.

Dislocation displacement effect on glide and climb mechanism, resulting in partial elimination of grain boundary, was noted before [6]. Diffusion of grain boundary area providing further grain coarsening can be considered as initial stage of processes of initial re-crystallization. Hindering of dislocations results in their lining up and then banding. It provides for appearance of fragmentation (polygonization) of grains (Figure 4) and stipulates increase of pore nucleation intensity. Newly formed carbide phases $\mathrm{VC}$ and $\mathrm{Mo}_{2} \mathrm{C}$ rise hindering of dislocation displacement, that also promotes formation of $\alpha$-phase grain polygonal structure. It should be noted that steam pipeline metal is subjected to simultaneous strengthening and softening [7] under typical for it aging condition with different intensity.

It is determined that the highest level of polygonization of $\alpha$-phase grains as well as effect of dislocation displacement is noted in area of incomplete recrystallization of HAZ metal. In this case the new products of austenite decay are globular pearlite located in form of fringes along the boundaries of actual austenite grains. Hindering of dislocations displacing by means of glide is mostly supported by sub-fine $\mathrm{VC}$ carbides, and $\mathrm{Mo}_{2} \mathrm{C}$ and $\mathrm{M}_{7} \mathrm{C}_{3}$ as well as $\mathrm{M}_{3} \mathrm{C}$ are somewhat less effective. It is important that carbides, particularly VC, have uniform distribution along the grain body and interfaces.

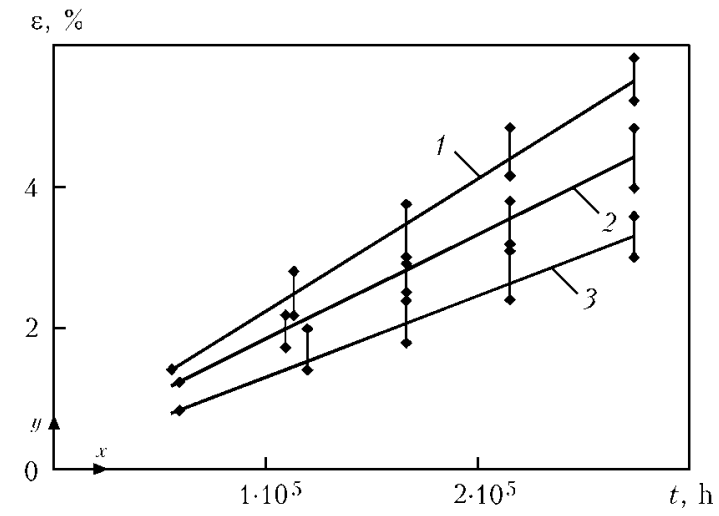

Figure 6. Dependence of residual deformation on structure of new products of austenite decay in area of HAZ metal incomplete re-crystallization: 1 - globular pearlite; $2-$ sorbite; 3 - troostite 


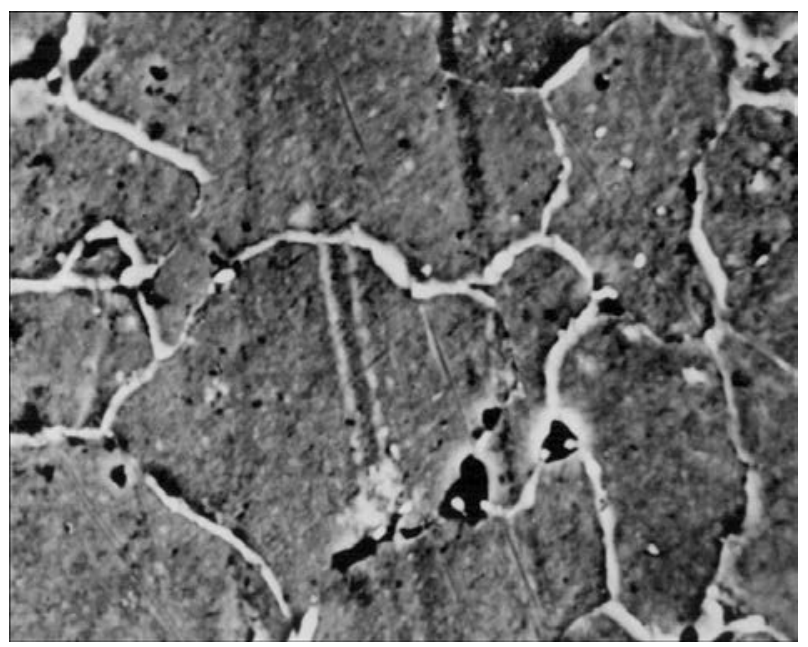

Figure 7. Creep pores on the $\alpha$-phase grain interface at $275,000 \mathrm{~h}$ running of welded joints $(\times 2500)$

At bulk deformation of welded joints of the steam pipelines less than $1 \%$ (running under creep conditions around 250,000 h), the areas of incomplete re-crystallization of HAZ metal (soft interlayer), according to data of F.A. Khromchenko [5], can be deformed by $6-8 \%$. It is determined [7] that, applicable to running of similar welded joints of around 276,000 h, its deformation makes 4-5\%. Level of deformation was determined on elements of the operating steam pipelines and in the specimens, being tested for long-term strength. Structure, fragmentation of $\alpha$-phase grains, lines and bands of glides were studied on specimens, cut out from the operating pipelines, that also proved their deformation level.

It was determined that the weld metal, having bainite structure (alloy of 09KhMFA type, base metal - $15 \mathrm{Kh} 1 \mathrm{M} 1 \mathrm{~F}$ grade steel), is characterized by the lowest creep rate in comparison with other initial structural conditions being allowed by reference documents. Value of the weld metal deformation, having a structure of upper

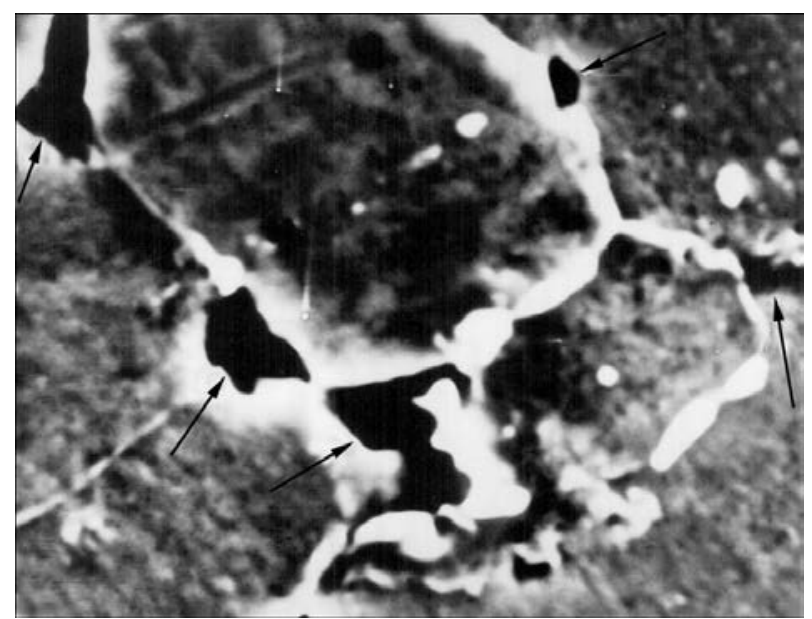

Figure 8. Form of creep pores (indicated by arrows) after welded joint running $(\times 3500) 276,000 \mathrm{~h}$

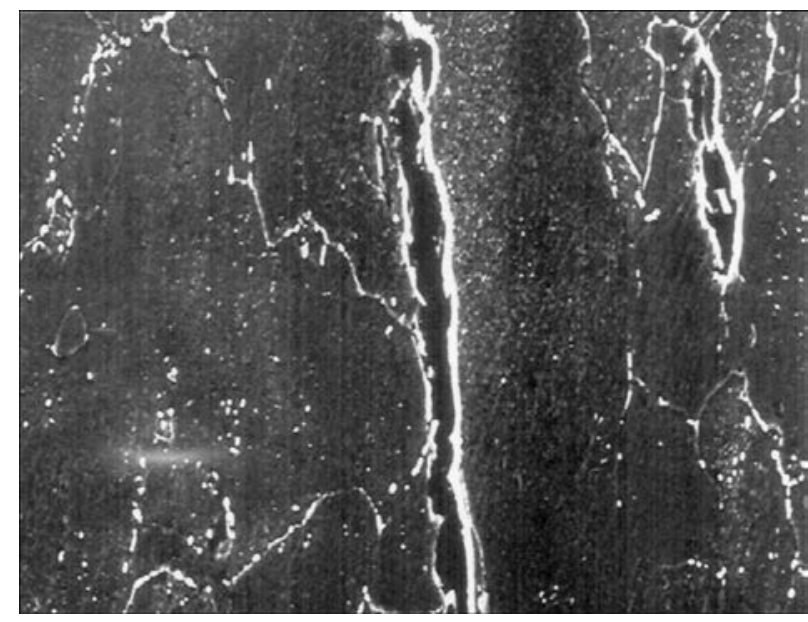

Figure 9. Creep crack in welded joint at 280,000 h running $(\times 2500)$

and lower tempered bainite, has insignificant difference (around 7-9 \%). It allows omitting its structural differences. It was found that metal of area of HAZ incomplete re-crystallization with structure, where the new austenite decay products represent globular pearlite (Figure 5), is deformed to larger extent than metal where the new products are sorbite, troostite or bainite (Figure 6). It should be noted that optimizing of welding thermal conditions allows preventing formation of the new austenite decay products in form of martensite or globular pearlite in this area [3].

Process of deformation of the welded joints provokes nucleation and propagation of creep pores in their metal. Pore detection was carried out on microsections, which were firstly subjected to mechanical polishing, and then electric polishing in strong orthophosphoric acid and further etching in $5 \% \mathrm{HNO}_{3}$. Indicated treatment was carried out 3-4 times on microsections from $12 \mathrm{Kh} 1 \mathrm{MF}$ steel, and from 5 to 7 times on mircosections from steel $15 \mathrm{Kh} 1 \mathrm{M} 1 \mathrm{~F}$ at presence of bainite constituent in their structure. The most

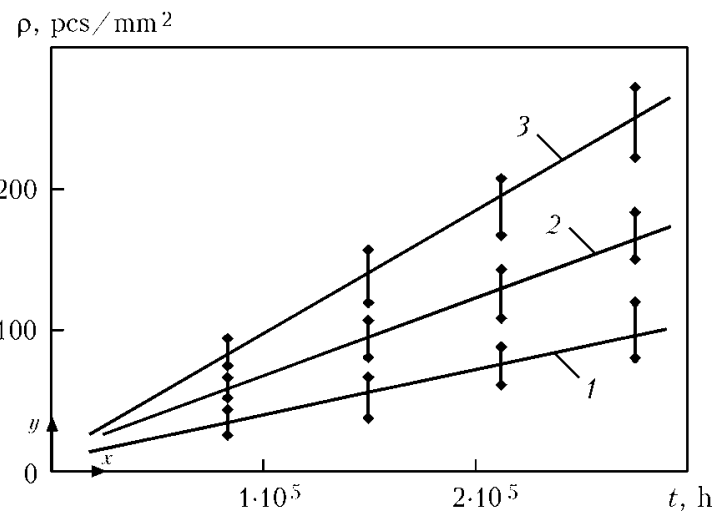

Figure 10. Dependence of density of creep pores of longitudinal $0.5-3.0 \mu \mathrm{m}$ size located on the $\alpha$-phase grain interface on numbers of austenite grains of area of HAZ metal overheating in welded joint from steel $15 \mathrm{Kh} 1 \mathrm{M} 1 \mathrm{~F}$ at 276,000 h running: $1-$ number $6 ; 2-5 ; 3-4$ 
intensive pore nucleation (Figure 7) is noted in the structure of area of HAZ metal incomplete re-crystallization, during its $4-6 \%$ deformation, at interface of two or three grains, where interfaces of austenite grains match with interface of grains of studied structure and coagulating carbides $\mathrm{M}_{23} \mathrm{C}_{6}$ are located. Amount of pores was significantly smaller at grain interface where was no coagulating carbides. From our point of view, pores of $0.03-0.07 \mu \mathrm{m}$ can be considered as nucleation ones. Formation of the nucleation pores can be considered as initial damageability stage. Creep pores in the welded joint metal are mainly formed along grain the interface and on their body (less intensively) normal to tensile stresses. Location of pores in the welded joints became chaotic in processes of their running $>250,000 \mathrm{~h}$. It should be noted that formation of pores was approximately $40-60 \%$ more than in the base metal in areas of fusion and HAZ metal incomplete re-crystallization (direct steam pipeline welded joints from steel $12 \mathrm{Kh} 1 \mathrm{MF}$, running $>270,000 \mathrm{~h}$ ). It makes $30 \%$ in overheating area. In process of development the form of pores became branched (Figure 8), and creep pores ( $\mathrm{Fi}_{-}$ gure 9), propagating on brittle mechanism, are formed in coalescence of the separate pores. Amount as well as intensity of propagation of pores and creep cracks depend on value of austenite grains (Figure 10) (GOST 5639-82), that is typical for areas of fusion and HAZ metal overheating.

Creep-rupture tests determined that critical level of residual deformation of area of HAZ metal incomplete re-crystallization in butt joints of the steam pipelines from $15 \mathrm{Kh} 1 \mathrm{M} 1 \mathrm{~F}$ steel should not exceed $1.5 \%$ and that for steel $12 \mathrm{Kh} 1 \mathrm{MF}$ makes $2 \%$ at their bulk deformation not less that $1 \%$, and its exceed promotes for rapid increase of pore formation intensity.

\section{Conclusions}

1. It is determined that structural changes of metal of long-lasting operation welded joints of the steam pipelines from steels $15 \mathrm{Kh} 1 \mathrm{M} 1 \mathrm{~F}$ and $12 \mathrm{Kh} 1 \mathrm{MF}$ are caused by diffusion processes, formation of segregations, displacement of chromium and molybdenum in the carbides and formation of new carbides, carbide reactions, nucleation and propagation of creep pores.

2. It is determined that reduction of level of structural inhomogeneity, formed under conditions of long-lasting operation of welded joints, results in decrease of intensity of creep pore formation.

1. SO 153-34.17.456-2003 (2005): Procedural recommendations on assessment of service life of heat power plants. Moscow: ORGRES.

2. OST 34-70-690-96: Metal of steam-power equipment of power plants. Methods of metallographic analysis in service conditions. Moscow: VTI.

3. SO 153-34.17.455-2003: Instruction on extension of service life of steam pipelines from centrifugal-cast pipes at heat power plants. Moscow: ORGRES

4. $R D$ 153-34.1-17.467-2001: Express method for evaluation of residual life of welded joints of boiler and steam pipeline collectors according to structural factor Moscow: ORGRES.

5. Khromchenko, F.A. (2002) Life of steam pipeline welded joints. Moscow: Mashinostroenie.

6. Elpanova, N.V., Berezina, T.G. (1989) Influence of structure on fracture kinetics of $12 \mathrm{Kh} 1 \mathrm{MF}$ steel at creep. Metallovedenie $i$ Termich. Obrab. Metallov, 7, 36-39.

7. Dmitrik, V.V. (2013) Welded joints of steam pipelines. Kharkov: Majdan.

8. Dmitrik, V.V., Bartash, S.N. (2014) Peculiarities of degradation of metal of welded joints of steam pipelines of heat power plants. The Paton Welding J., 6/7, 29-30

9. Dmitrik, V.V., Bartash, S.N. (2010) Features of damageability of steam pipeline welded joints by the creep mechanism. Ibid., 6, 19-21.

10. Butyagin, P.Yu. (2006) Chemical physics of solids. Moscow: MGU. 